\title{
Análisis de Monómero Residual en Envases de Poliestireno Grado Alimenticio
}

\author{
Perla Martínez, Saira Magaly Floresª Jesús Rodolfo Páez ${ }^{\mathrm{a}}$ María Guadalupe Sánchezª \\ ${ }^{2}$ Universidad Autónoma de Nuevo León, UANL, Facultad de Ciencias Químicas, Av. Universidad S/N Ciudad Universitaria San Nicolás de \\ los Garza Nuevo León CP 66451 México. Tel (81) 83-29-40-00. \\ *E-mail: magsa73@yahoo.com.mx \\ Recibido 16 de abril de 2012, Aceptado 14 de mayo de 2012
}

\section{Resumen}

En el presente trabajo se realizó el análisis de estireno residual en vasos de poliestireno mediante espectroscopia infrarroja; así mismo, se determinaron las condiciones del análisis cromatográfico tanto de HPLC como de cromatografía de gases, para determinar la concentración de este monómero en vasos grado alimenticio. Una muestra de vasos de poliestireno se disolvió en acetona, se precipitó con metanol, el extracto concentrado fue analizado bajo determinadas condiciones de cromatografía de líquidos de alta resolución, así como cromatografía de gases. Se prepararon estándares de diferente concentración con el fin de determinar el límite de detección de cada técnica cromatográfica. Mediante HPLC se alcanzó una sensibilidad de 25 ppm, que es muy alta, por lo que este tipo de muestras no pueden ser analizadas con las condiciones cromatográficas del presente estudio. La concentración mínima detectada mediante cromatografía de gases fue 2.0 ppm, el monómero residual presente en muestras de vasos de poliestireno se detectó previamente de manera cualitativa por FT-IR y semicuantitativa por cromatografia de gases.

\section{Introducción}

Los polímeros son macromoléculas (generalmente orgánicas) formadas por la unión de unidades repetitivas denominadas monómeros, los cuales se combinan unos con otros mediante una reacción de polimerización [1]. Las reacciones de polimerización más comunes a nivel industrial son poliadición y policondensación; por lo tanto, una de las clasificaciones de los polímeros de acuerdo a la manera en la que fue sintetizado es polímeros de adición, por ejemplo poliestireno, policloruro de vinilo, poliacrilatos, etc. y polímeros de condensación, como polietilentereftalato, poliuretano, melamina, etc [2].

El poliestireno (PS) es un polímero de adición termoplástico que se obtiene de la polimerización del estireno; existen cuatro tipos principales: el PS cristal, que es transparente, rígido y quebradizo; el poliestireno de alto impacto, resistente y opaco, el poliestireno expandido el cual es muy ligero, y el poliestireno extrusionado, similar al expandido pero más denso e impermeable. Una de las aplicaciones principales del PS cristal y espumado es la fabricación de envases para conservar alimentos, estos envases, específicamente vasos, se procesan mediante extrusión y termoformado. Cuando el alimento llega al consumidor final, generalmente los vasos son sometidos a un proceso de calentamiento en horno de microondas, o se le añaden directamente líquidos calientes. En este proceso es probable que migre estireno residual hacia el contenido del vaso, y que sea ingerido por el consumidor; el límite máximo de estireno residual permitido por la FDA es $0.5 \%[3,4]$, este límite está basado en los niveles de toxicidad. Para el envasado de alimentos se recomienda un máximo de
$0.25 \%$ de estireno residual, ya que cantidades mayores producen olor desagradable al alimento contenido en los envases, esto además de la toxicidad inherente a este compuesto $[5,6]$.

El estireno (vinilbenceno) es un hidrocarburo aromático, líquido incoloro de aroma dulce que se evapora fácilmente, a menudo contiene otros productos químicos que le dan un aroma penetrante y desagradable.

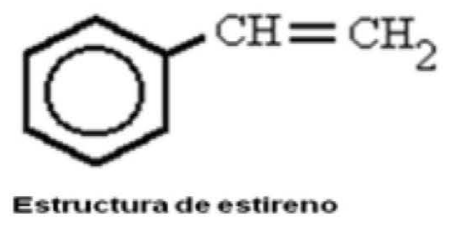

Mediante técnicas cromatógraficas de líquidos y gases se puede determinar la presencia de monómero residual en vasos grado alimenticio [7-10], así mismo se puede caracterizar por infrarrojo para corroborar la presencia de este monómero, el cual se espera que esté en cantidad menor a $1.0 \mathrm{ppm}$. Se ha reportado también la determinación de estireno residual en poliestireno utilizando técnicas espectrofotométricas en el rango del ultravioleta. Sin embargo, el valor que se reporta en estos trabajos ( $0.02 \%)$ está sujeto a un error muy alto debido a la poca exactitud de la técnica.

El que los envases grado alimenticio contengan monómero residual se considera dañino para la salud, si el consumo de este es mayor a 20 ppm según la norma establecida por la Organización Mundial de la Salud [11-13]. 


\section{Parte experimental}

Reactivos y Equipo

Metanol grado HPLC (Fermont, $99.98 \%$ ), agua grado HPLC (Fermont), acetona (Aldrich, $99.5 \%$ ), metanol (Aldrich, $99.6 \%$ ), estireno (CTR, $99.8 \%$ ). Cromatógrafo de Líquidos de alta resolución Varian Modelo 9065, Cromatógrafo de gases Varian Modelo 3700.

\section{Metodología}

Se prepararon estándares de estireno de $12.5,25,50$, 75 y $100 \mathrm{ppm}$ y se inyectaron al cromatógrafo de líquidos bajo las siguientes condiciones: fase móvil metanol, flujo $1 \mathrm{~mL} / \mathrm{min}$, detector arreglo de diodos, columna ODS $25 \mathrm{~cm}$ x $1.8 \mathrm{~mm}$, volumen inyectado 10 $\mu \mathrm{L}$.

Adicionalmente se prepararon estándares de 2.0, 4.0, 8.0 y $10.0 \mathrm{ppm}$ y se inyectaron al cromatógrafo de gases bajo las siguientes condiciones: Columna $20 \% \mathrm{Rtx}-52$ $\mathrm{m} \times 2 \mu \mathrm{m}$, malla $100 / 120$, Inyector $250^{\circ} \mathrm{C}$, Detector $250^{\circ} \mathrm{C}$ temperatura inicial $40^{\circ} \mathrm{C}$, rampa de calentamineto $4^{\circ} \mathrm{C} / \mathrm{min}$., temperatura final $250^{\circ} \mathrm{C}$, detector FID, flama Hidrogeno, aire acarreador Nitrógeno.

Para el tratamiento de la muestra un vaso de poliestireno espumado grado alimenticio fue cortado en piezas de aproximadamente $1 \mathrm{~cm}^{2}$, se tomaron $2.0 \mathrm{~g}$ de esta muestra y se disolvieron en acetona hasta la desaparición del color blanco que imparte el poliestireno, después se añadió metanol gota a gota con agitación constante hasta precipitación completa del poliestireno, se agitó la solución durante 15 minutos y se filtró a vacío. La solución resultante se concentró a $70^{\circ} \mathrm{C}$ con ayuda de un rotavapor, el residuo se pasó a través de un microfiltro de $45 \mu \mathrm{m}$ y se aforó $\mathrm{a} 25 \mathrm{~mL}$ con metanol, esta fracción se inyectó a los cromatógrafos de líquidos y gases con las mismas condiciones utilizadas para el análisis cromatográfico de los estándares.

Al finalizar el análisis mediante cromatografía, las muestras se llevaron a sequedad evaporándolas a $70^{\circ} \mathrm{C}$, el residuo se analizó mediante FTIR.

\section{Resultados y discusión}

En la Figura 1 se observa el espectro IR obtenido del extracto proveniente de la muestra, el cual presenta las bandas de los grupos funcionales del estireno: $\mathrm{C}-\mathrm{H}$ a 2920 y $2650 \mathrm{~cm}^{-1}, \mathrm{CH}_{2}=\mathrm{CH}_{2}$ a $1720 \mathrm{~cm}^{-1}$ y el grupo aromático monosustituído a 1590 y $1450 \mathrm{~cm}_{-1}$, además fue identificado por la biblioteca integrada del equipo como estireno, por lo que resultó positiva la presencia de monómero residual en vasos de poliestireno grado alimenticio, por lo cual se procedió a la cuantificación mediante cromatografia de líquidos de alta resolución.

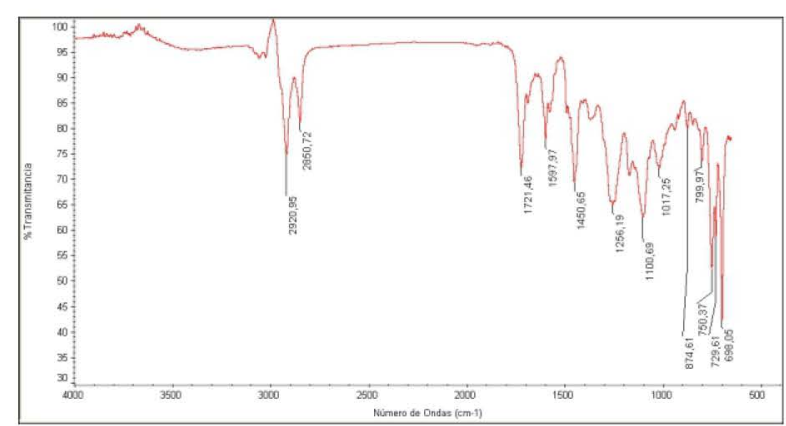

Figura 1. Espectro FTIR del extracto proveniente de un vaso de poliestireno.

Mediante HPLC y bajo las condiciones cromatográficas indicadas arriba, el tiempo de retención del estireno fue 3.4 minutos, los estándares se inyectaron por triplicado; en la Tabla 1 se muestra el promedio del área bajo la curva obtenida para cada estándar, por lo que se puede apreciar, el límite de detección con esta técnica analítica fue $25 \mathrm{ppm}$, valor relativamente alto si se considera que se pretende cuantificar el monómero residual en envases de alimentos, y que el valor que se espera en este tipo de muestras debe ser inferior a $10 \mathrm{ppm}$, por lo estos parámetros cromatográficos serán aplicados para determinar la concentración de estireno en muestras diferentes a poliestireno grado alimenticio.

Tabla 1. Área bajo la curva obtenida mediante HPLC en estándares de estireno.

\begin{tabular}{|c|c|}
\hline Estándar (ppm) & $\begin{array}{c}\text { Área bajo la } \\
\text { curva }\end{array}$ \\
\hline 100 & 10867 \\
\hline 75 & 8765 \\
\hline 50 & 6907 \\
\hline 25 & 3902 \\
\hline 12.5 & $\mathrm{ND}$ \\
\hline
\end{tabular}

Mediante cromatografía de gases se logró detectar hasta $2.0 \mathrm{ppm}$ de estireno, en la Tabla 2 se muestra un promedio del área obtenida para cada uno de los estándares inyectados por triplicado. El área bajo la curva correspondiente al estándar de 2.0 ppm se integró con muy baja señal, lo que indica que este es el límite de sensibilidad que se puede alcanzar bajo estas condiciones cromatográficas en este equipo. 
Tabla 2. Área bajo la curva obtenida mediante cromatografía de gases en estándares de estireno.

\begin{tabular}{|c|c|}
\hline Estándar (ppm) & $\begin{array}{c}\text { Área bajo la } \\
\text { curva }\end{array}$ \\
\hline 2.0 & 2.6 \\
\hline 4.0 & 10.7 \\
\hline 8.0 & 30.1 \\
\hline 10.0 & 38.4 \\
\hline
\end{tabular}

En la Figura 2 parte superior se muestra el cromatograma correspondiente al estándar de 2.0 ppm, mientras que en el cromatograma de abajo en la misma figura, se observa el cromatograma de la fracción extraída de un vaso de poliestireno, el pico que aparece en el mismo tiempo de retención que el estireno estándar, no se integró bajo las mismas condiciones de análisis, lo que demuestra que el contenido de estireno residual en el vaso desechable es menor a $2.0 \mathrm{ppm}$. Sin embargo, mediante las técnicas de cromatografía de gases e infrarrojo, se demuestra la presencia de estireno residual en vasos de poliestireno.

Con el fin de determinar de manera semicuantitativa el estireno residual, se procedió a adicionar el estándar de $2.0 \mathrm{ppm}$ a la muestra del vaso e inyectarla al cromatografo de gases, de esta manera observar si aumenta el área bajo la curva. El área bajo la curva obtenida para el estándar de $2.0 \mathrm{ppm}$ con la muestra adicionada, aumentó a 3.1. Si el área del estándar dio 2.6 (ver Tabla 2) se presupone que el estireno está presente en la muestra en concentración alrededor de $0.32 \mathrm{ppm}$. Este es un análisis que se realizó solamente con el fin de determinar si mediante el método de adición de estándar, el cual se desarrollará en un trabajo a continuación del presente, será posible de manera cuantitativa bajar la sensibilidad del equipo con el fin de detectar cantidad menor a $1.0 \mathrm{ppm}$ de estireno residual en envases grado alimenticio.

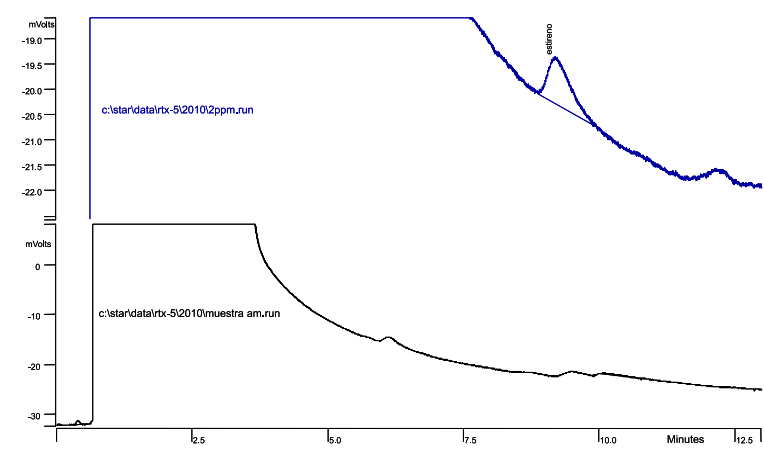

Figura 2. Cromatogramas de gases:

a) estándar con $2.0 \mathrm{ppm}$ de estireno

b) extracción de un vaso de poliestireno.

\section{Conclusiones}

Mediante las técnicas analíticas de HPLC y CG se alcanzó un límite de detección de estireno residual en vasos de poliestireno de 25 y 2.0 ppm respectivamente. La presencia de este monómero fue detectada cualitativamente mediante FT-IR después del análisis cromatográfico al evaporar el disolvente.

Las muestras analizadas contienen menos de 1.0 ppm utilizando adición del estándar de $2.0 \mathrm{ppm}$ a la muestra, de manera semicuantitativa se detectó 0.32 ppm, este resultado obliga a pensar que mediante la técnica por adición de estándar en cromatografía de gases, la cual se desarrollará en un trabajo subsecuente, será posible determinar cuantitativamente el estireno residual presente en vasos de poliestireno, así como en otros tipos de envases del mismo material, tal como platos, charolas, etc.

Mediante las condiciones establecidas en este trabajo para la técnica de HPLC no se recomienda analizar estireno residual en este tipo de muestras, ya que el límite de detección es alto, dicha técnica se utilizará para analizar el estireno residual en poliestireno sintetizado para aplicaciones industriales no alimenticias, el cual se supone que contiene una mayor cantidad de estireno residual.

\section{Agradecimientos}

Los autores agradecen al Departamento de Servicios Profesionales de la Facultad de Ciencias Químicas por las facilidades brindadas en esta investigación.

\section{Referencias}

1. George Odian, Principles of Polimerization, Third Edition, John Willey \& Sons, Inc., New York, 2004, 6-10.

2. R. Seymour and C. Carraher, "Introducción a la Química de los Polímeros." Ed. Reverté, 1995.

3. Food and Drug Administration, CFR 177.1640, 21, 3, 2011.

4. López, J., Balart, R., Sánchez, L. and Jiménez, A. "Reciclability of polystyrene in solids wastes." New Developments in Chemistry and Biochemistry, Nova Science Publishers Inc., New York, 2003.

5. N. Nagai, T. Matsunobe and T. Imai. "Infrared Analysis of Depth Profiles in UV Photochemical Degradation of Polymers." Polymer Degradation and Stability, 2004, 88, 224-233.

6. J. JÄRVISALO, P. PFÄFFLI, H. VAINIO. "Industrial Hazards of plastic and syntetic elastomers". Institute of Occupational Health Helsinki, Finland. "Proceedings of the International Symposium on Occupational Hazards Related to Plastic and Synthetic Elastomers", Espoo, Finland, 1982, 22-27.

7. J.E.Neweel; Analytical Chemistry, 1972, 3, 445-448.

8. De Forero, Irma B.; De Rascovsky, Elisa G.; De Ruiz, M.; Del Carmen, S.; Plásticos, 1971, 19, 122-125.

9. Tweet, O.; Miller, W.K.; Analytical Chemistry; 1973, 35, 7, 852854.

10. Kolobova, V. N.; Zharkov, V. V. Materialy Tret'ego Ural'sk. Soveshch. po Spektroskopii, Inst. Fiz. Metal., Akad. Nauk SSSR, Komis. po Spektroskopii, Sverdlovsk, 1962, 178-9.

11. OMS; Styrene in drinking-water, 2003, (WHO/SDE/WSH/0304/27). 
12.Instituto Nacional de Seguridad e Higiene en el trabajo, Fichas de seguridad Quimica, ICSC:0073.

13. López, J., Balart, R., Sánchez, L., and Nadal, A. "Application of thermal analysis to the study of recycled polymer materials in blends and degradation."Polymer Analysis and Degradation, Nova Science Publishers Inc., New York, 2000. 